\title{
Intestinal parasitosis and associated factors among diabetic patients attending Arba Minch Hospital, Southern Ethiopia
}

\author{
Getaneh Alemu $^{1 *}\left(\mathbb{D}\right.$, Abdu Jemal $^{2}$ and Zerihun Zerdo ${ }^{2}$
}

\begin{abstract}
Objective: Local assessment of the magnitude of intestinal parasitic infections and associated factors among diabetic patients helps for good prognosis of diabetes. Hospital based cross-sectional study was conducted by recruiting 215 diabetic patients. A structured questionnaire was used to capture data about socio-demographic characteristics, clinical history and factors associated with intestinal parasitosis. Stool samples were collected and processed by direct wet mount, formol-ether concentration and modified ziehl-Neelson staining techniques. All data were analyzed using Statistical Package for Social Sciences software version 20.

Results: The rate of intestinal parasitic infection among diabetic patients was 19.5\%. Cryptosporidium parvum accounts the highest frequency (18, 8.4\%) followed by Ascaris lumbricoides (8, 3.7\%). Presence of domestic animals in the house $(A O R=2.857,95 \% \mathrm{Cl} 1.290-6.330, p=0.010)$, manifestation of abdominal pain ( $A O R=3.716,95 \% \mathrm{Cl}$ $1.632-8.459, p=0.002)$ and farmer and labor occupation ( $A O R=3.695,95 \% \mathrm{Cl} 1.082-12.618, \mathrm{p}=0.037)$ were significantly associated with intestinal parasitosis. The magnitude of intestinal parasitosis among diabetic patients attending Arba Minch Hospital was considerable. Hence, we recommend routine screening and prompt treatment for intestinal parasitosis in order to improve the health of diabetic patients.
\end{abstract}

Keywords: Intestinal parasites, Diabetes mellitus, Opportunistic parasites

\section{Introduction}

Diabetes mellitus (DM) is a clinical syndrome manifested by chronic hyperglycemia. It is caused by defects in insulin secretion, action or both [1]. Diabetes mellitus results from either autoimmune destruction of insulin producing beta cells of the pancreas or insulin resistance, a condition in which cells fail to properly use insulin. Globally, an estimated 422 million adults were living with diabetes in 2014 [2]. In 2015, diabetes was the direct cause of 1.6 million deaths [3]. In sub-Saharan Africa, over 12 million people are expected to have DM, and 330,000 of these people will die from DM related complications [4]. In Ethiopia, according to the World Health Organization (WHO) estimation, the number of diabetic cases in the

\footnotetext{
*Correspondence: getanehmlt@gmail.com

${ }^{1}$ Department of Medical Laboratory Sciences, Bahir Dar University, Bahir Dar, Ethiopia

Full list of author information is available at the end of the article
}

year 2000 was 800,000 and this number is expected to increase to 1.8 million by the year 2030 [5].

Recently, it has been demonstrated that both innate and adaptive immune responses are impaired in DM patients [6]. As a result, they are easily affected by infectious causes of morbidity. Intestinal protozoa and helminths use this opportunity to cause more aggressive and chronic form of morbidity among DM patients. Previous surveys from Iran (24.4-26.3\%), Tehran province (15.6\%), Cameroon (10\%), Nigeria (18.7\%) and Egypt (25-39\%) indicated that considerable proportions of DM patients host intestinal parasites [6-12].

Intestinal parasites (IPs) are among the most widespread causes of human infections worldwide [10]. However, the species distribution differs region to region because of variations in environmental, social, and geographical factors. They spread mostly in areas with poor sanitation and are most common in tropical countries [13]. Moreover, the clinical significance and associated 
risk factors is more related to, and extensively studied in children considering them as at higher risk than the other population groups. However, as observed in our previous study among tuberculosis patients, adolescents and adults with certain co-existing chronic diseases are also at high risk of infection with intestinal parasites [14]. Therefore, local data about the magnitude and predominating species of parasites helps to formulate effective control strategies in order to improve the health of chronically ill people like DM patients. Despite this, there is paucity of information in Ethiopia. Hence the aim of the present study was to assess the burden of intestinal parasitosis and pre-disposing factors among DM patients attending Arba Minch Hospital, Southern Ethiopia.

\section{Main text \\ Materials and methods Study design and area}

A hospital based cross-sectional study was conducted in Arba Minch diabetes clinic from March to May, 2017. Arba Minch is located in the southern part of the country about $454 \mathrm{kms}$ from Addis Ababa, the capital of Ethiopia. In the town, there is one hospital (Arba Minch Hospital) and two health centers. The Hospital was built in 1961 to serve around 500,000 people, but now it is serving for more than two million people. Over 100,000 patients visit the hospital every year. The hospital gives services under different departments, of which, diabetes unit is the one. Diagnosis, treatment, counseling and follow up of DM patients are the main activities of the diabetes unit.

\section{Study participants}

The source population of the present study was all patients visiting diabetes clinic of Arba Minch Hospital (AMH). The study population comprises of all diabetic patients attending diabetes clinic of AMH during the study period. Those diabetic patients whose age $\geq 12$ years old were included in the study but those who were seriously sick and unable to respond to the research questions and/or taking anti-parasitic drugs within 15 days before data collection were excluded. Sample size was determined using sample size determination for estimation of single population proportion formula. Taking $18.7 \%$ prevalence of IPs from previous similar study [10], 95\% confidence interval $(Z=1.96)$ and $5 \%$ margin of error $(d=0.05)$, the initial sample size was 234 . By considering a $5 \%$ (12 subjects) non response rate, the final sample size was determined to be 246 . The sampling technique was based on systematic random selection method by calculating kth value. The number of diabetic patients visiting $\mathrm{AMH}$ during the same period in the year 2016 was 684 . Hence $K=684 / 246=3$. The first participant was recruited by lottery method and then every 3rd subject was included in the study.

\section{Data collection}

Data related to socio-demographic characteristics of study participants, and potential factors for intestinal parasitosis were collected by face to face interview using a pre-tested structured questionnaire. After obtaining consent from the participants, about $2 \mathrm{~g}$ of fresh fecal samples were collected from each participant and placed in labeled dry, clean, leak proof, tight lid plastic stool container. A portion of stool was examined in Arba Minch Hospital Parasitology laboratory by direct wet mount with saline $(0.85 \%$ sodium chloride solution) to detect the presence of motile parasites and trophozoites within $30 \mathrm{~min}$ after collection. The remaining samples were preserved using $10 \% \mathrm{v} / \mathrm{v}$ formol saline and transported to Microbiology and Parasitology Laboratory of Arba Minch University for further process. A portion of the preserved stool was processed by the formol-ether concentration technique for microscopic detection of ova and cyst of IPs. The modified ziehl-Neelson staining technique was used to detect oocysts of intestinal coccidia like cryptosporidium, Isospora, and cyclospora spp. All laboratory procedures were conducted following standard protocols [15].

\section{Statistical analysis}

Data were cleaned, entered and analyzed using Statistical Package for Social Sciences software version 20. Descriptive statistics were calculated to describe the study population characteristics. Bivariate regression was used to assess associations between dependent and independent categorical variables. Multivariate regression model then followed for variables with $\mathrm{p} \leq 0.25$ in the bivariate analysis. Association between variables was considered statistically significant only if $\mathrm{p}$-value $<0.05$ at $95 \%$ confidence level.

\section{Results}

\section{Socio-demographic characteristics of study participants}

A total of $244 \mathrm{DM}$ patients participated in the study. However, 29 (11.9\%) were unable to provide stool sample. Hence data from 215 participants was complete for analysis. From the total of 215 participants, 56.7\% (122/215) were male and $43.3 \%$ (93/215) were female. Their mean age was 36.02 years with standard deviation of 9.165 (Table 1).

\section{Prevalence of intestinal parasites}

Among 215 study participants, IPs were detected from $42(19.5 \%)$ diabetic patients and the remaining 173 $(80.5 \%)$ were negative for IP. Out of the IPs detected, 
Table 1 Socio-demographic characteristics of diabetic patients in Arba Minch hospital from March to May, 2017 $(\mathrm{n}=\mathbf{2 1 5})$

\begin{tabular}{lc}
\hline Characteristics & $\begin{array}{c}\text { Frequency } \\
\text { (percentage) }\end{array}$ \\
\hline Age of respondents & \\
$16-25$ & $28(13.0 \%)$ \\
$26-35$ & $75(34.9 \%)$ \\
$36-45$ & $80(37.2 \%)$ \\
$\geq 46$ & $32(14.9 \%)$ \\
Sex & \\
Male & $122(56.7 \%)$ \\
Female & $93(43.3 \%)$ \\
Marital status & \\
Single & $70(32.6 \%)$ \\
Married & $145(67.4 \%)$ \\
Educational status & \\
Unable to read and write & $42(19.5 \%)$ \\
Primary & $63(29.3 \%)$ \\
Secondary and above & $110(51.2 \%)$ \\
Occupation & \\
Government employee & $58(27.0 \%)$ \\
Merchant & $56(26.0 \%)$ \\
Farmer and labor & $26(12.1 \%)$ \\
Student & $20(9.3 \%)$ \\
House wife & $55(25.6 \%)$ \\
Residence & \\
Rural & $181(84.2 \%)$ \\
\hline & $34(15.8 \%)$ \\
\hline
\end{tabular}

Table 2 Prevalence of intestinal parasites among diabetic patients in Arba Minch hospital from March to May, 2017 $(n=215)$

\begin{tabular}{lc}
\hline Type of parasite & Frequency (\%) \\
\hline Cryptosporidium spp. & $18(8.4)$ \\
Ascaris lumbricoides & $8(3.7)$ \\
Hook worm & $4(1.9)$ \\
Trichuris trichuria & $4(1.9)$ \\
Gardia lamblia & $6(2.8)$ \\
Teania spp & $2(0.9)$ \\
\hline
\end{tabular}

Cryptosporidium spp was with the highest frequency (18, 8.4\%) followed by A.lumbricoides $(8,3.7 \%)$ and G. lamblia $(6,2.8 \%)$ (Table 2).

\section{Factors associated with intestinal parasites}

In the present study, Male participants showed higher infection rate $(27,12.6 \%)$ as compared to female participants $(15,6.9 \%)$. However, the difference was not statistically significant $(p=0.273)$. Participants with age group 36-45 years were more affected than the other group $(17,7.9 \%)$ but the difference was not significant. The study showed that intestinal parasitic infections were significantly associated with presence of domestic animals in the house ( $\mathrm{AOR}=2.857,95 \%$ $\mathrm{CI}=1.290-6.330, \mathrm{p}=0.010)$, manifestation of abdominal pain $(\mathrm{AOR}=3.716,95 \% \mathrm{CI}=1.632-8.459, \mathrm{p}=0.002)$ and farmer and labor occupation $(\mathrm{AOR}=3.695,95 \%$ $\mathrm{CI}=1.082-12.618, \mathrm{p}=0.037$ ) (Table 3$)$.

\section{Discussion}

The magnitude of intestinal parasitosis in the present study (19.5\%) was similar with findings from Nigeria (18.7\%) [10]. However, it was lower than the prevalence reported in Iran (24.4\% to 26.3\%) [6, 7] and Egypt (25\%) [11]. Difference in laboratory techniques used might bring these magnitude variations; for example, the study conducted in Iran used Kinyoun acid-fast staining to detect Cryptosporidium, and modified trichrome stain (Ryan-Blue) for detection of Microsporidia [6]. The modified Ziehl-Neelson diagnostic technique, we used, couldn't detect Microsporidia which in turn lowers the overall IP prevalence. The number of specimens collected and examined in order to rule out infection also matters. In the present study only single specimen was collected and examined from each participant despite it is recommended to examine specimens collected in three nonconsecutive days [15].

Oocysts of Cryptosporidium spp (8.4\%) were the most frequently detected parasites in the present study. The prevalence was higher than study findings conducted in Cameroon (0.67\%) [9], Iran (2.45\%) [7] and Sohag University hospitals, Egypt (5\%) [11]. Giardia lamblia (3.6\%) and Entamoeba histolytica (6.7\%) were the commonest parasites detected from diabetic patients according to studies from Cameroon and Iran respectively $[9,11]$. High geographical distribution of Cryptosporidium spp in Ethiopia might bring this difference [16]. Zoonotic transmission of Cryptosporidium may also have a role as we find significant association between intestinal parasitosis and presence of domestic animals in the house $(\mathrm{p}=0.010)$. Rate of Cryptosporidium infection is associated with level of immune depletion. Hence having immune profile data of study participants would help us to give firm justification about high rate of Cryptosporidiosis in the present study.

Male participants were at higher risk of acquiring IP infection $(22.1 \%)$ compared to females $(16.1 \%)$ but the difference was not significant $(\mathrm{p}=0.273)$. This goes in line with findings from Iran and Nigeria [6, 7, 11]. Diabetic patients who reported presence of domestic animals in 
Table 3 Factors associated with intestinal parasitic infection among DM patients in Arba Minch Hospital from MarchMay, 2017

\begin{tabular}{|c|c|c|c|c|c|c|}
\hline Variables & $\begin{array}{l}\text { Number } \\
\text { examined }\end{array}$ & Rate of IPIs (\%) & COR $(95 \% \mathrm{Cl})$ & p-value & AOR $(95 \% \mathrm{Cl})$ & $p$-value \\
\hline \multicolumn{7}{|l|}{ Age } \\
\hline $16-25$ & 28 & $2(0.9)$ & & & & \\
\hline $26-35$ & 75 & $14(6.5)$ & $0.335(0.071-1.581)$ & 0.167 & $0.012(0.001-0.168)$ & 0.061 \\
\hline $36-45$ & 80 & $17(7.9)$ & $0.285(0.061-1.323)$ & 0.109 & $0.357(0.107-1.188)$ & 0.093 \\
\hline$\geq 46$ & 32 & $9(4.2)$ & $0.197(0.038-1.005)$ & 0.051 & $0.431(0.144-1.285)$ & 0.131 \\
\hline \multicolumn{7}{|l|}{ Sex } \\
\hline Male & 122 & $27(12.6)$ & $0.677(0.336-1.361)$ & 0.273 & & \\
\hline Female & 93 & $15(6.9)$ & & & & \\
\hline \multicolumn{7}{|l|}{ Marital status } \\
\hline Single & 70 & $17(7.9)$ & & & & \\
\hline Married & 145 & $25(11.6)$ & $1.540(0.768-3.087)$ & 0.224 & $2.101(0.987-4.471)$ & 0.054 \\
\hline \multicolumn{7}{|l|}{ Educational status } \\
\hline Un able to read and write & 42 & $11(5.1)$ & $0.626(0.270-1.453)$ & 0.276 & & \\
\hline Primary & 63 & $11(5.1)$ & $1.051(0.467-2.364)$ & 0.905 & & \\
\hline Secondary and above & 110 & $20(9.3)$ & & & & \\
\hline \multicolumn{7}{|l|}{ Occupation } \\
\hline Governm't & 58 & $8(3.7)$ & 1.389 (0.504-3.825) & 0.525 & & \\
\hline Merchant & 56 & $11(5.1)$ & $0.909(0.351-2.353)$ & 0.844 & & \\
\hline Farmer and labor & 26 & $10(4.7)$ & $0.356(0.125-1.012)$ & 0.053 & $3.695(1.082-12.618)$ & 0.037 \\
\hline Student & 20 & $3(1.4)$ & $1.259(0.309-5.136)$ & 0.748 & & \\
\hline Housewife & 55 & $10(4.7)$ & & & & \\
\hline \multicolumn{7}{|l|}{ Residence } \\
\hline Urban & 181 & $33(15.3)$ & & & & \\
\hline Rural & 34 & $9(4.2)$ & $0.619(0.265-1.449)$ & 0.269 & & \\
\hline \multicolumn{7}{|l|}{ Food source } \\
\hline At home & 185 & $36(16.7)$ & $1.035(0.394-2.718)$ & 0.945 & & \\
\hline From hotel & 30 & $6(2.8)$ & & & & \\
\hline \multicolumn{7}{|l|}{ Habit of eating raw vegetables } \\
\hline Yes & 175 & $34(15.8)$ & $1.037(0.439-2.451)$ & 0.934 & & \\
\hline No & 40 & $8(3.7)$ & & & & \\
\hline \multicolumn{7}{|l|}{ Water source } \\
\hline Pipe water & 211 & $40(18.6)$ & & & & \\
\hline River/other & 4 & $2(0.9)$ & $0.234(0.032-1.711)$ & 0.152 & $0.173(0.018-1.645)$ & 0.127 \\
\hline \multicolumn{7}{|l|}{ Swimming habit } \\
\hline Yes & 37 & $7(3.3)$ & $1.049(0.426-2.585)$ & 0.917 & & \\
\hline No & 178 & $35(16.3)$ & & & & \\
\hline \multicolumn{7}{|l|}{ Domestic animal at home } \\
\hline Yes & 80 & $22(10.2)$ & $2.181(1.102-4.317)$ & 0.025 & $2.857(1.290-6.330)$ & 0.010 \\
\hline No & 135 & $20(9.3)$ & & & & \\
\hline \multicolumn{7}{|l|}{ Washing hands after toilet } \\
\hline Yes & 180 & $33(15.3)$ & & & & \\
\hline No & 35 & $9(4.2)$ & $1.542(0.661-3.596)$ & 0.316 & & \\
\hline \multicolumn{7}{|l|}{ Abdominal pain } \\
\hline Yes & 62 & $19(8.8)$ & $2.497(1.242-5.022)$ & 0.010 & $3.716(1.632-8.459)$ & 0.002 \\
\hline No & 153 & $23(10.7)$ & & & & \\
\hline
\end{tabular}


the house were approximately 3 times (AOR $=2.857 ; 95 \%$ CI $1.290-6.330 \mathrm{p}=0.010$ ) at higher risk of acquiring IP infection. The fact that Cryptosporidium spp are the most common findings, which are transmitted to humans from cattle, makes the association justifiable. Gastrointestinal discomfort is a common clinical manifestation during IP infection that DM patients who were infected with IP were 3.7 times $(\mathrm{AOR}=3.716 ; 95 \%$ CI $1.632-8.459$, $\mathrm{p}=0.002$ ) at higher risk of having abdominal pain in the present study. DM patients with farmer and labor occupation were also at higher risk of infection $(p=0.037)$ as most intestinal parasites are transmitted when contacting contaminated soil and water. According to the present study, level of education, occupation, and source of food and water, swimming habit, habit of eating raw fruits/ vegetables were not significantly associated with intestinal parasitic infections among diabetic patients. The Small number of participants we recruited is a limitation for not generating strong data about factors associated with intestinal parasitosis.

\section{Conclusion}

In conclusion we, probably for the first time, have shown the rate of intestinal parasitic infections among diabetic patients in Ethiopia. The magnitude of intestinal parasitic infections among DM patients in Arba Minch Hospital was considerable when viewed from the patients' side. This is because DM causes immune dysfunction which enables parasites to act aggressively and cause severe pathology. Hence, we recommend routine screening and prompt treatment for intestinal parasitosis in order to improve the health of diabetic patients.

\section{Limitations}

Magnitude of intestinal parasitosis among different types of DM, Immunological profile of patients and parasite load were not assessed in the present study, all because of logistic problems.

\section{Abbreviations \\ AMH: Arba Minch Hospital; AOR: adjusted odds ratio; COR: crude odds ratio; DM: diabetes mellitus; IP: intestinal parasites.}

\section{Authors' contributions}

AJ conceived and designed the project. AJ, GA and ZZ performed the experiment, analyzed the data, and wrote the paper. All authors read and approved the final manuscript.

\section{Author details}

${ }^{1}$ Department of Medical Laboratory Sciences, Bahir Dar University, Bahir Dar, Ethiopia. ${ }^{2}$ Department of Medical Laboratory Sciences, Arba Minch University, Arba Minch, Ethiopia.

\section{Acknowledgements}

The authors thank Arba Minch Hospital laboratory technologists for their contribution during data collection and Arba Minch University for giving ethical clearance. The authors'regards also go to the study participants for giving their consent to participate in the study.

\section{Competing interests}

The authors declare that they have no competing interests.

Availability of data and materials

The original data for this study is available from the corresponding author.

\section{Consent for publication}

Not applicable.

\section{Ethics approval and consent to participate}

Ethical approval was obtained from ethical review board of Arba Minch University, College of Medicine and Health Sciences. According to ethics guideline of Arba Minch University, getting verbal consent is enough in order to collect questionnaire data and biological samples collected by noninvasive procedures (stool, urine, sputum). Hence, verbal consent and assent was obtained from each respondent or parent. All laboratory results were promptly communicated to patients so that they could get treatment in the DM clinic.

\section{Funding}

No fund was obtained for execution of the study.

\section{Publisher's Note}

Springer Nature remains neutral with regard to jurisdictional claims in published maps and institutional affiliations.

Received: 13 August 2018 Accepted: 25 September 2018

Published online: 01 October 2018

\section{References}

1. Abebe D, Tassachew Y, Adem J, Reshad N, Delelegn S. Diabetes mellitus for the Ethiopian health center team, 2005. http://ncdsynergies.org/plann ing_tool/diabetes-mellitus-training-materials-for-ethiopia/.

2. WHO. Global report on diabetes mellitus, 2016. http://apps.who.int/iris/ bitstream/handle/10665/204871/9789241565257_eng.pdf;jsessionid $=2919 F 5053023848$ BACAA590CB8508884? sequence $=1$.

3. WHO. Diabetes fact sheet. Updated November 2017. http://www.who. int/diabetes/en/.

4. Motala A, Ramaiya K. Diabetes: the hidden pandemic and its impact on sub-Saharan Africa. Africa: Diabetes leadership forum; 2010.

5. Gebre MW. Diabetes mellitus and associated diseases from Ethiopian perspective: systematic review. Ethiop J Health Dev. 2013;27(3):249-53.

6. Mohtashamipour M, Ghaffari Hoseini Sh, Pestehchian N, Yousefi H, Fallah E, Hazratian T. Intestinal parasitic infections in patients with diabetes mellitus: a case-control study. J Anal Res Clin Med. 2015;3(3):157-63.

7. Bafghi AF, Ardekan MA, Tafti AD. Frequency distribution of intestinal parasitic infections in diabetic patients-Yazd. Iran J Diabetes Obes. 2015;7(1):33-7.

8. Akhlaghi L, Gharavi M, Faghihi A, Jabbari M. Survey on the prevalence rates of intestinal parasites in diabetic patients in Karaj and Savodjbolagh cities. RJMS. 2005;12(45):23-9.

9. Tangi FB, Focal EB, Longdoh NA, Eteneneng EJ. Intestinal parasites in diabetes mellitus patients in the Limbe and Buea municipalities, Cameroon. Diabetes Res Open J. 2016;2(1):1-7.

10. Akinbo FO, Olujobi SO, Omoregie R, Egbe C. Intestinal parasitic infections among diabetes mellitus patients. J Biomarkers Genomic Med. 2013:5:44-7.

11. Elnadi NA, Hassanien HA, Ahmad AM, Abdellah AK. Intestinal parasites in diabetic patients in Sohag university Hospitals, Egypt. J Egypt Soc Parasitol. 2015;45(2):443-9.

12. Sabah AA, Temsah AG. Prevalence of some gastro-intestinal parasites in diabetic patients in Tana City, gharbia governorate, Egypt. J Egypt Soc Parasitol. 2015;45(3):681-4.

13. Mengestie $\mathrm{H}$. Prevalence of intestinal parasitic infections among people with and without HIV infection and their association with diarrhea in 
Debre Markos town, east Gojjam zone, Ethiopia; 2014. https://docplayer. net/22661334-M-sc-thesis-hiwotie-mengestie-may-2014-haramayauniversity.html.

14. Getaneh A, Mohammedaman M. Intestinal helminth co-infection and associated factors among tuberculosis patients in Arba Minch, Ethiopia. BMC Infect Dis. 2017;17(16):68. https://doi.org/10.1186/s12879-12017 $-12195-12871$.
15. Cheesbrough M. Parasitological tests. District laboratory practices in tropical countries. Cambridge: Cambridge University Press; 2000.

16. Gedle D, Kumera G, Eshete T, Ketema K, Adugna H, Feyera F. Intestinal parasitic infections and its association with undernutrition and CD4T cell levels among HIV/AIDS patients on HAART in Butajira, Ethiopia. J Health Popul Nutr. 2017;36:15. https://doi.org/10.1186/s41043-017-0092-2.
Ready to submit your research? Choose BMC and benefit from:

- fast, convenient online submission

- thorough peer review by experienced researchers in your field

- rapid publication on acceptance

- support for research data, including large and complex data types

- gold Open Access which fosters wider collaboration and increased citations

- maximum visibility for your research: over $100 \mathrm{M}$ website views per year

At BMC, research is always in progress.

Learn more biomedcentral.com/submissions 